\title{
Study of the Aluminothermic Reduction of Niobium Pentoxide through Thermal Analysis Experiments and High Energy Milling Processing
}

\author{
Claudio Parra De Lazzari, Danielle Goya Simões, José Deodoro Trani Capocchi* \\ Department of Metallurgical and Materials Engineering, \\ Polytechnic School of the University of São Paulo, \\ Av. Prof. Mello Moraes 2463, Cidade Universitária, 05508-900 São Paulo - SP, Brazil
}

Received: April 2, 2007; Revised: May 30, 2007

\begin{abstract}
Aluminothermic reduction of niobium pentoxide was studied through thermal analysis techniques such as differential thermal analysis (DTA) and thermogravimetry (TG) as well as through high energy milling processing. Reactants mixtures were composed by powders of $\mathrm{Nb}_{2} \mathrm{O}_{5}$ and $\mathrm{Al}$. In the case of DTA-TG experiments, different molar ratios $\mathrm{Nb}_{2} \mathrm{O}_{5}$ :Al were heated in a dynamic atmosphere of synthetic air under controlled conditions. The high energy milling runs were carried out via SPEX vibratory mill under argon atmosphere and with milling power equal to 7:1 (ratio of mass of balls to mass of mixture) with 10 pct excess of Al over the stoichiometric mass of aluminum necessary. In both kinds of experiments, $\mathrm{X}$ ray diffraction was used in order to identify the products of reaction. From DTA-TG experiments, it was possible to determine the experimental value of the enthalpy change $\left(-595.9 \mathrm{~kJ} \cdot \mathrm{mol}^{-1}\right)$, which is near to the theoretical one. From the milling experiments, it was possible to verify the possibility of the occurance of aluminothermic reducion of niobium pentoxide via this kind of processing.
\end{abstract}

Keywords: aluminothermy, niobium pentoxide, thermal analysis, high energy milling

\section{Introduction}

Metallothermic reactions are very important for many refractory metals producing processes. The heat of reaction and the rate of reaction are essential for the understanding of the metallurgical operations involved. Since the aluminothermic reduction of metal oxides is both highly exothermic and rapid reactions, there are few attempts to study the kinetics of such a process ${ }^{1-3}$.

The aluminothermic reduction of $\mathrm{Cr}_{2} \mathrm{O}_{3}{ }^{4}, \mathrm{Fe}_{2} \mathrm{O}_{3}^{5,6}, \mathrm{MnO}_{2}{ }^{6,7}$ and $\mathrm{V}_{2} \mathrm{O}_{5}{ }^{7}$, have been studied using the simultaneous differential thermal analysis (DTA) - thermogravimetry (TG) techniques. In a DTA apparatus the heat losses cannot be accurately predicted, therefore it is impossible to estimate precisely the maximum temperature attainable by aluminothermic reacting mixtures in a DTA set-up. Therefore an excess of aluminium has been used in order to use the excess enthalpy ${ }^{4-7}$.

In terms of high energy milling, this is a process used for producing powders having a fine microstructural scale and/or as a technique for alloying difficult or normally incompatible materials. The capability of high energy milling process to produce powders with unique microstructures has been clearly established and this process is also inherently flexible ${ }^{8-10}$.

In high energy milling, a suitable powder charge (typically, a blend of elemental or preallyoed powders) is placed in a high-energy mill, along with a suitable grinding medium (typically, hardened steel balls). From a macroscopic viewpoint, the resultant powder develops through the repeated cold working and fracture of the powder particles with a final composition corresponding to the percentages of the respective constituents in the initial charge. This technique has been utilized to producing a wide range of materials including amorphous materials, intermetallic compounds, and solid solution alloys ${ }^{9-12}$.

In the case of a vibratory mill like SPEX, it is possible to produce small quantities of mechanically alloyed powder in relatively short times. In this system, the ball and powder charges are placed in a small jar which is agitated at a high frequency in a complex cycle which involves motion in three orthogonal directions ${ }^{8-10}$.
In the present work, aluminothermic reduction of niobium pentoxide was studied through thermal analysis techniques such as differential thermal analysis (DTA) and thermogravimetry (TG) as well as through high energy milling processing. Reactants mixtures were composed by powders of $\mathrm{Nb}_{2} \mathrm{O}_{5}$ and $\mathrm{Al}$. In the case of DTA-TG experiments, different molar ratios $\mathrm{Nb}_{2} \mathrm{O}_{5}: \mathrm{Al}$ were heated in a dynamic atmosphere of synthetic air under controlled conditions. The high energy milling runs were carried out via SPEX vibratory mill under argon atmosphere and with milling power equal to $7: 1$ (ratio of mass of balls to mass of mixture) with 10 pct excess of $\mathrm{Al}$ over the stoichiometric mass of aluminum necessary. In both kinds of experiments, $\mathrm{X}$ ray diffraction was used in order to identify the products of reaction.

\section{Experimental}

\subsection{Thermal analysis experiments (DTA-TG)}

The DTA-TG experiments were carried out in a STA 409 model of NETZSCH-Gerätebau $\mathrm{GmbH}$. The reactant mixtures were composed of powder of $\mathrm{Nb}_{2} \mathrm{O}_{5}(98.80 \mathrm{wt}$. (\%) purity, average size 24.75 micrometers) and powder of $\mathrm{Al}(99.70 \mathrm{wt}$. (\%) purity, average size 41.48 micrometers), with different molar ratios of $\mathrm{Nb}_{2} \mathrm{O}_{5}: \mathrm{Al}(1: 5$, 1:7, 1:8, 1:9, 1:10, 1:11, 1:12).

In each run a sample weighing $40 \mathrm{mg}$ was put into alumina cylindrical crucible and heated from room temperature up to $1200{ }^{\circ} \mathrm{C}$ in a dynamic atmosphere of synthetic air $\left(\mathrm{O}_{2}+\mathrm{N}_{2}=99.997\right.$ vol. (\%), $100 \mathrm{~mL} / \mathrm{min}$ ). Alumina powder was used as reference material. The adopted heating rate was $10{ }^{\circ} \mathrm{C} / \mathrm{min}$.

$\mathrm{X}$ ray diffraction was used in order to identify the products of reduction.

\subsection{High energy milling experiments}

The experiments were carried out via vibratory high energy milling. A SPEX CertPrep 8000 Mixer/Mill was used for milling 
under argon atmosphere (99,999 vol. (\%) purity). A tool steel jar and chromium steel balls were used. The milling power ratio was $7: 1$ (ratio of mass of balls to mass of mixture) and runs were carried out for periods of 45, 75 e 120 minutes. For each milling, the reactant mixture was prepared from powders of $\mathrm{Nb}_{2} \mathrm{O}_{5}(98.80 \mathrm{wt}$. (\%) purity, average size 24.75 micrometers) and $\mathrm{Al}$ (99.70 wt. (\%) purity, average size 41.48 micrometers), with 10 pct excess of $\mathrm{Al}$ over the stoichiometric mass of aluminum necessary for the reduction of the niobium oxide to metallic niobium. The temperature of the jar was monitored by means of type $\mathrm{K}$ thermocouple, in connection with a data collector.

$\mathrm{X}$ ray diffraction was used in order to identify the products of reduction.

\section{Results and Discussion}

\subsection{Thermal analysis experiments (DTA-TG)}

Figure 1 shows typical DTA-TG curves generated. On the DTA curve one can see two peaks as follows: a) the endothermic peak related to the melting of aluminium; and b) the exothermic peak related to the overall enthalpy change of the system. On the other hand, on the TG curve one can see the mass gain related to the oxidation of part of the excess of aluminium of the mixture. According to Sarangi, Sarangi, Ray and Misra ${ }^{5}$ the exothermic DTA peak represent the total heat effect due to the following factors: a) heat of the aluminothermic reaction (exothermic with no gain of mass); b) heat of oxidation of some excess of aluminium (exothermic with gain of mass); and c) dissolution of the reduced metal (niobium) in excess of aluminium and formation of intermetallic compounds (of the $\mathrm{Al}-\mathrm{Nb}$ system) (exothermic with no gain of mass).

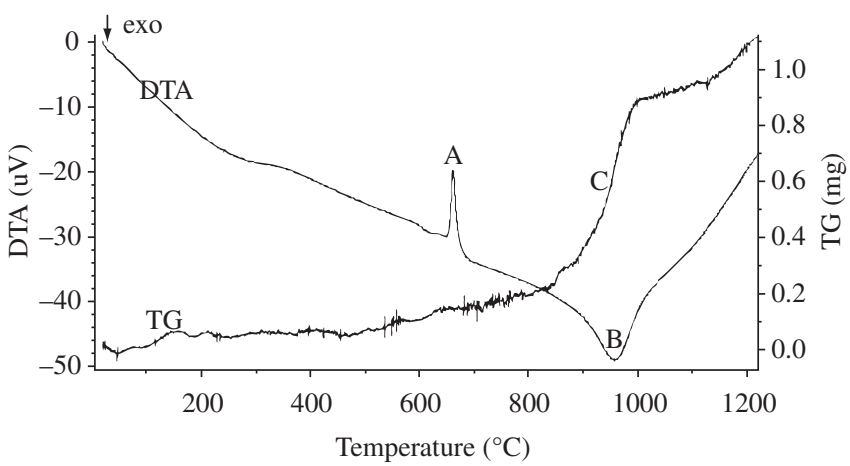

Figure 1. DTA and TG curves for the mixture with molar ratio $\mathrm{Nb}_{2} \mathrm{O}_{5}: \mathrm{Al}=1: 11$. A (DTA curve): endothermic peak related to the melting of aluminium; B (DTA curve): exothermic peak related to the aluminothermic reduction of $\mathrm{Nb}_{2} \mathrm{O}_{5}$ plus the oxidation of part of the aluminium in excess plus the formation of an intermetallic compound of $\mathrm{Al}-\mathrm{Nb}$ system $\left(\mathrm{NbAl}_{3}\right)$; and $\mathrm{C}$ (TG curve): mass gain related to the oxidation of part of the aluminium in excess.
The heats of formation at $298 \mathrm{~K}$ of the intermetallic compounds of the $\mathrm{Al}-\mathrm{Nb}$ system $\left(\mathrm{Nb}_{2} \mathrm{Al}, \mathrm{Nb}_{3} \mathrm{Al}\right.$ and $\left.\mathrm{NbAl}_{3}\right)$ are very small in comparison with the heat of reaction of aluminothermic reduction of $\mathrm{Nb}_{2} \mathrm{O}_{5}$. They are equal respectively to ${ }^{13}-29.8 \mathrm{~kJ} \cdot \mathrm{mol}^{-1},-19.7 \mathrm{~kJ} \cdot \mathrm{mol}^{-1}$ and $-49.4 \mathrm{~kJ} . \mathrm{mol}^{-1}$ while the heat of reduction of $\mathrm{Nb}_{2} \mathrm{O}_{5}$ with $\mathrm{Al}$ $\left(\mathrm{Nb}_{2} \mathrm{O}_{5}(\mathrm{~s})+10 / 3 \mathrm{Al}(\mathrm{s}, 1)=2 \mathrm{Nb}(\mathrm{s})+5 / 3 \mathrm{Al}_{2} \mathrm{O}_{3}(\mathrm{~s})\right)$ is $-890.0 \mathrm{~kJ} \cdot \mathrm{mol}^{-1}$, at $25^{\circ} \mathrm{C}(298 \mathrm{~K})^{14}$. Therefore, the experimental heat value of the aluminothermic reduction of $\mathrm{Nb}_{2} \mathrm{O}_{5}$ was obtained by subtracting the heat of oxidation of some excess of aluminium calculated from the gain of mass detected on the TG curve from the overall enthalpy change calculated from the DTA peak. The results of the experiments are summarised in Table 1 which contains: the molar ratio used in each experiment, mass of mixture, the DTA temperature of the exothermic peak, the calculated overall enthalpy change of the system, the mass gain, the enthalpy of oxidation of the aluminium and, finally, the experimentally determined enthalpy change associated to the reduction of $\mathrm{Nb}_{2} \mathrm{O}_{5}$ with $\mathrm{Al}$.

Figure 2 shows, for each tested molar ratio $\mathrm{Nb}_{2} \mathrm{O}_{5}: \mathrm{Al}$, both the theoretical and the experimental values of the enthalpy change of the reduction, at the respective DTA peak temperature. The calculated values of the enthalpy of reduction presented on Figure 2 have been calculated from the sum of the change of enthalpy corresponding to the reduction at $298 \mathrm{~K}$ plus variation of the heat capacities of the products of reaction from $298 \mathrm{~K}$ up to the corresponding peak temperatures.

It must be noted that for molar ratios $\mathrm{Nb}_{2} \mathrm{O}_{5}: \mathrm{Al}$ equal or greater than $1: 11$ the experimental value of the enthalpy change is almost constant and very near to the theoretical value (approximately $6 \%$ less than the theoretical value).

Figure 3 shows the $\mathrm{X}$ ray diffraction pattern of the product reaction for the molar ratio $\mathrm{Nb}_{2} \mathrm{O}_{5}: \mathrm{Al}=1: 11$ which indicates the presence of

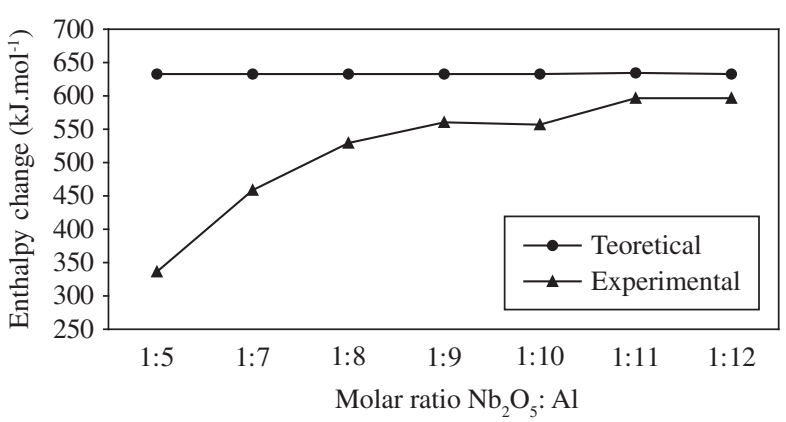

Figure 2. Theoretical and experimental values of the enthalpy change $\left(\mathrm{kJ} . \mathrm{mol}^{-1}\right)$ of the reduction for each tested molar ratio $\left(\mathrm{Nb}_{2} \mathrm{O}_{5}: \mathrm{Al}\right)$, at the respective DTA peak temperature.

Table 1. Consolidated results of the experiments.

\begin{tabular}{ccccccc}
\hline $\begin{array}{c}\mathrm{Nb}_{2} \mathrm{O}_{5}: \mathrm{Al} \\
(\mathrm{molar} \text { ratio })\end{array}$ & $\begin{array}{c}\text { Mass of } \\
\text { mixture }(\mathrm{mg})\end{array}$ & $\begin{array}{c}\text { DTA peak } \\
\text { temperature }\left({ }^{\circ} \mathrm{C}\right)\end{array}$ & $\begin{array}{c}\text { Overall enthalpy } \\
\text { change }(\mathrm{kJ})\end{array}$ & $\begin{array}{c}\text { Mass gain } \\
(\mathrm{mg})\end{array}$ & $\begin{array}{c}\text { Enthalpy of } \\
\text { oxidation }(\mathrm{kJ})\end{array}$ & $\begin{array}{c}\text { Experimental enthalpy change of the } \\
\text { reduction }\left(\mathrm{kJ} . \mathrm{mol}^{-1}\right)\end{array}$ \\
\hline $1: 5$ & 20.9 & 969.9 & -0.026 & 0.39 & -0.010 & -335.8 \\
$1: 7$ & 20.1 & 968.7 & -0.030 & 0.44 & -0.012 & -457.9 \\
$1: 8$ & 20.7 & 969.5 & -0.033 & 0.47 & -0.013 & -529.4 \\
$1: 9$ & 20.7 & 968.6 & -0.034 & 0.52 & -0.014 & -559.9 \\
$1: 10$ & 21.1 & 969.6 & -0.035 & 0.58 & -0.016 & -556.1 \\
$1: 11$ & 20.5 & 967.5 & -0.036 & 0.66 & -0.018 & -595.9 \\
$1: 12$ & 21.6 & 969.2 & -0.041 & 0.75 & -0.020 & -595.7 \\
\hline
\end{tabular}


$\mathrm{NbAl}_{3}, \mathrm{Al}_{2} \mathrm{O}_{3}$ and unreacted $\mathrm{Al}$ and $\mathrm{Nb}_{2} \mathrm{O}_{5}$. Each individual phase was identified using ICDD - International Centre for Diffraction Data.

The presence of the intermetallic compound $\mathrm{NbAl}_{3}$ is due to the fact that there is aluminium in excess over the stoichiometric quantity (3.3 more than the stoichiometric quantity). So, the reduced niobium reacts with the excess of aluminium leading to the formation of $\mathrm{NbAl}_{3}$. Sarangi et al. ${ }^{7}$ have observed in the case of the reduction of $\mathrm{V}_{2} \mathrm{O}_{5}$ and $\mathrm{MnO}_{2}$ with $\mathrm{Al}$ the formation of $\mathrm{V}-\mathrm{Al}$ and $\mathrm{Mn}-\mathrm{Al}$ intermetallic compounds, respectively. Cintho et al. ${ }^{8}$ have observed in the case of the reduction of $\mathrm{Cr}_{2} \mathrm{O}_{3}$ with $\mathrm{Al}$ the formation of $\mathrm{Cr}-\mathrm{Al}$ intermetallic compound.

\subsection{High energy milling experiments}

Figure 4 shows the $\mathrm{X}$ ray diffraction pattern of the mixture homogeneized during 1 hour (without milling). Figures 5, 6 and 7 show $\mathrm{X}$ ray diffraction patterns of the mixtures milled during 45,75 and 120 minutes, respectively.

It must be noted in Figure 4 (mixture only homogeneized - not milled) and in Figure 5 (mixture milled for 45 minutes) that the peaks of the diffraction correspond only to the presence of the reactants $\mathrm{Nb}_{2} \mathrm{O}_{5}$ and $\mathrm{Al}$. However, in the diffraction pattern related to the mix-

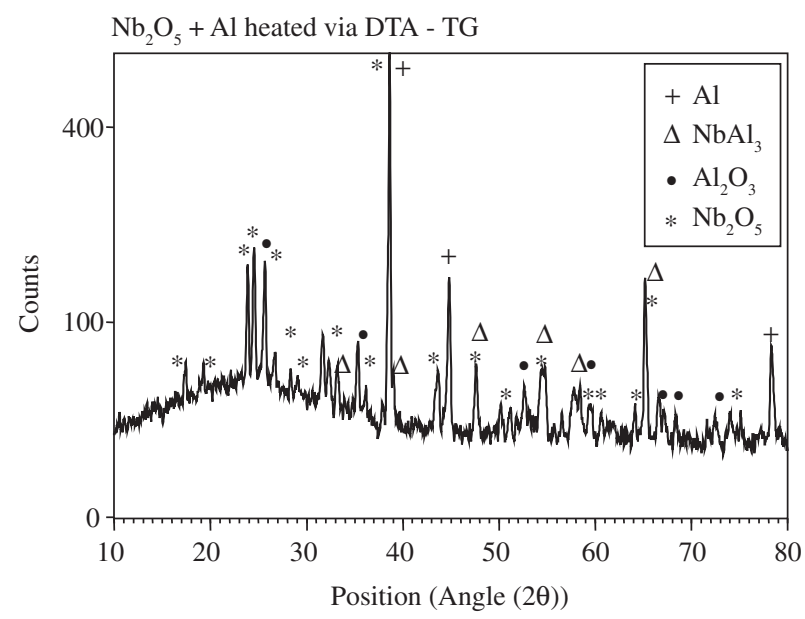

Figure 3. XRD pattern of reduction of $\mathrm{Nb}_{2} \mathrm{O}_{5}$ with $\mathrm{Al}$ (molar ratio $\mathrm{Nb}_{2} \mathrm{O}_{5}$ : $\mathrm{Al}=1: 11$ ). Anode: $\mathrm{Cu}$, Generator tension: $40 \mathrm{kV}$, Generator current: $40 \mathrm{~mA}$, $\mathrm{K} \alpha_{1}=1.54060 \AA$. Phases were identified according to ICDD - International Centre for Diffraction Data.

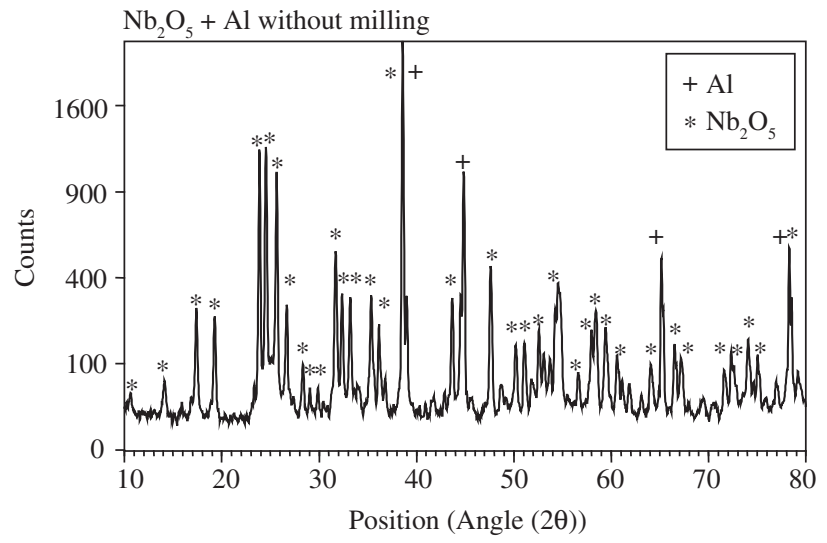

Figure 4. XRD pattern of sample homogeneized during 1 hour (without milling). Anode: $\mathrm{Cu}$, Generator tension: $40 \mathrm{kV}$, Generator current: $40 \mathrm{~mA}$, $\mathrm{K} \alpha_{1}=1.54060 \AA$. Phases were identified according to ICDD - International Centre for Diffraction Data.

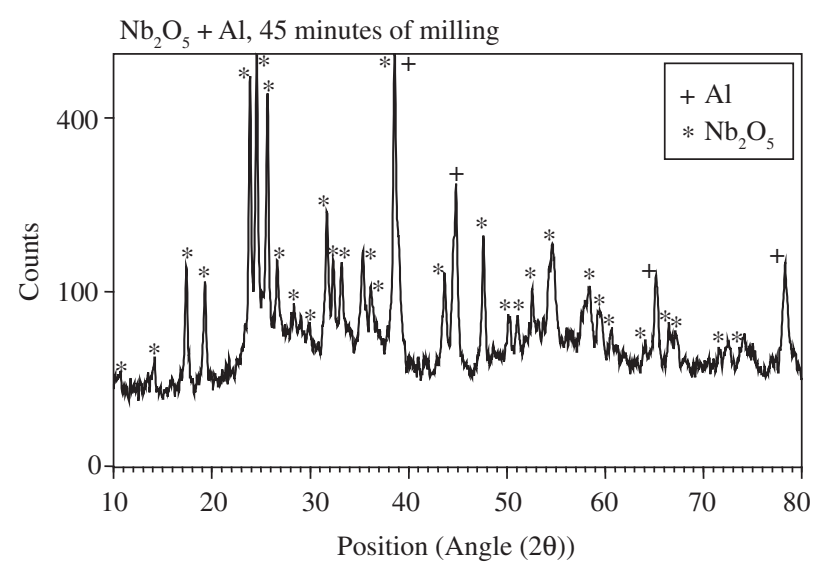

Figure 5. XRD pattern of reaction products, after 45 minutes of milling. Anode: $\mathrm{Cu}$, Generator tension: $40 \mathrm{kV}$, Generator current: 40 minutes mA, $\mathrm{K} \alpha_{1}=1.54060 \AA$. Phases were identified according to ICDD - International Centre for Diffraction Data.

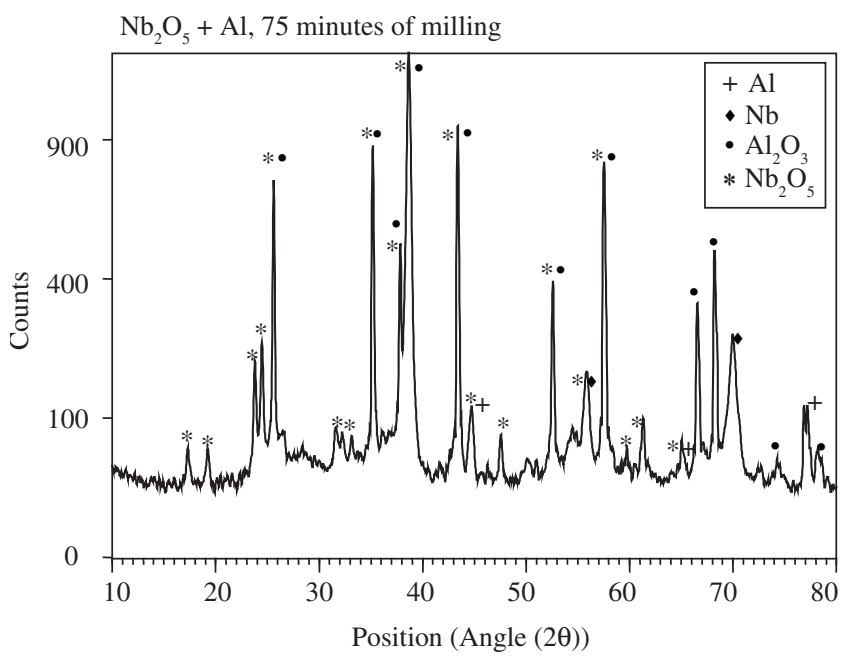

Figure 6. XRD pattern of reaction products, after 75 minutes of milling. Anode: $\mathrm{Cu}$, Generator tension: $40 \mathrm{kV}$, Generator current: $40 \mathrm{~mA}$, $\mathrm{K} \alpha_{1}=1.54060 \AA$. Phases were identified according to ICDD - International Centre for Diffraction Data.

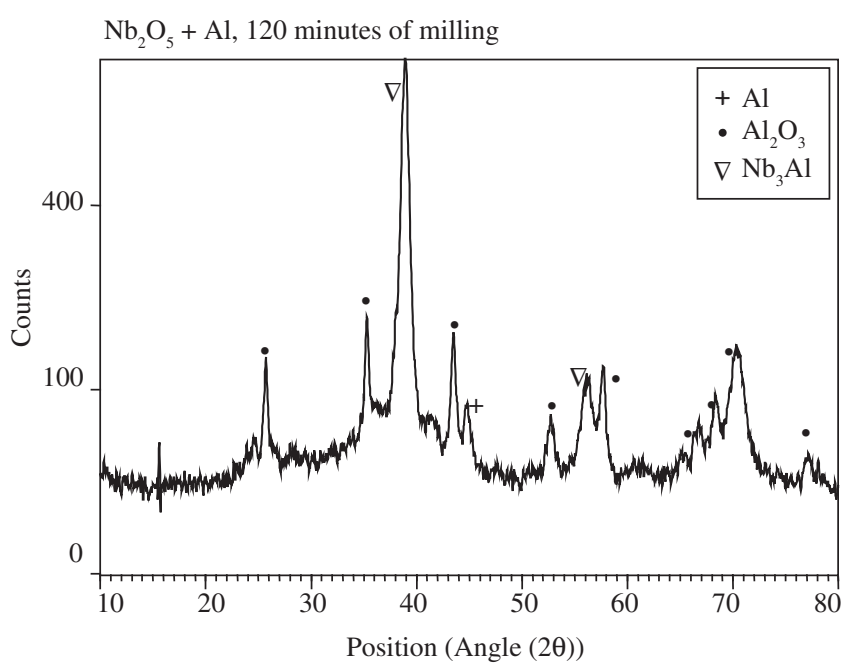

Figure 7. XRD pattern of reaction products, after 120 minutes of milling. Anode: $\mathrm{Cu}$, Generator tension: $40 \mathrm{kV}$, Generator current: $40 \mathrm{~mA}$, $\mathrm{K} \alpha_{1}=1.54060 \AA$. Phases were identified according to ICDD - International Centre for Diffraction Data. 
ture milled for 75 minutes, it is possible to notice a reduction in the intensities of peaks related to the presence of $\mathrm{Nb}_{2} \mathrm{O}_{5}$ and the appearance of peaks related to the presence of $\mathrm{Al}_{2} \mathrm{O}_{3}$ and $\mathrm{Nb}$, generated from the aluminothermic reduction of niobium pentoxide. Finally, in the diffraction pattern related of the mixture milled for 120 minutes, it is possible to verify the presence of peaks related to $\mathrm{Al}_{2} \mathrm{O}_{3}$, residual $\mathrm{Al}$ and intermetallic compound $\mathrm{Nb}_{3} \mathrm{Al}$; the last one generated from the reaction between the residual aluminium and the niobium obtained from the aluminothermic reduction.

Figure 8 shows the temperature evolution of the jar during the 120 minutes milling run.

From Figure 8, it is possible to verify an abrupt increase of the temperature and the existance of a characteristic milling time related to the beginning of reaction (about 75 minutes).

\section{Conclusion} study:

The following conclusions have been obtained from the present

- For molar ratios $\mathrm{Nb}_{2} \mathrm{O}_{5}$ : $\mathrm{Al}$ equal or greater than 1:11 the experimental value of the enthalpy change is almost constant $\left(-595.9 \mathrm{~kJ} \mathrm{~mol}^{-1}\right)$ and very near to the theoretical value (approximately $6 \%$ less than the theoretical value). The analysis of the product of reaction for the molar ratio $\mathrm{Nb}_{2} \mathrm{O}_{5}: \mathrm{Al}=1: 11$ indicates the presence of $\mathrm{NbAl}_{3}, \mathrm{Al}_{2} \mathrm{O}_{3}$ and unreacted $\mathrm{Al}$ and $\mathrm{Nb}_{2} \mathrm{O}_{5}$.

- $\mathrm{X}$ ray diffraction patterns of the mixtures milled allowed to verify the possibility of the occurance of aluminothermic reduction of niobium pentoxide via high energy milling processing. For 120 minutes milling time, the reaction products were $\mathrm{Al}_{2} \mathrm{O}_{3}$ and intermetallic compound $\mathrm{Nb}_{3} \mathrm{Al}$, with the presence of some residual $\mathrm{Al}$.

\section{Acknowledgments}

The authors gratefully acknowledge the financial support of Fundação de Amparo à Pesquisa do Estado de São Paulo - FAPESP and of Conselho Nacional de Desenvolvimento Científico e Tecnológico - CNPq.

\section{References}

1. Habashi F. Principles of Extractive Metallurgy. New York: Gordon and Breach; 1986. p. 19.

2. White JH. The Extraction of Metals. New York: Macmillan and Co; 1968. p. 56.

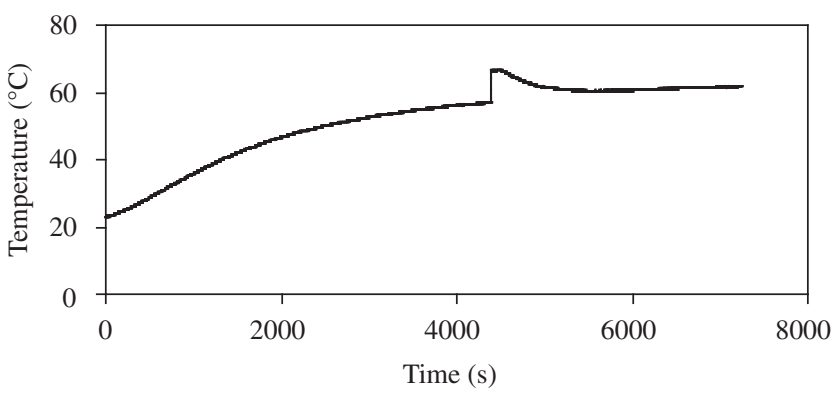

Figure 8. Temperature profile of the jar during milling.

3. Rosenqvist T. Principles of Extractive Metallurgy. New York: Mc Graw-Hill; 1974. p. 34-416.

4. Cintho OM, De Lazzari CP, Capocchi JDT. Kinetics of the non-isothermal reduction of $\mathrm{Cr}_{2} \mathrm{O}_{3}$ with aluminium. ISIJ International. 2004; 44(5):781-784.

5. Sarangi A, Sarangi B, Ray HS, Misra S. Thermoanalytical investigation of the aluminothermic reduction of iron (III) oxide. Journal of Thermal Analysis. 1990; 36(2):513-527.

6. Sarangi B, Sarangi A, Ray HS. Kinetics of aluminothermic reduction of $\mathrm{MnO}_{2}$ and $\mathrm{Fe}_{2} \mathrm{O}_{3}$ : a thermoanalytical investigation. ISIJ International. 1996; 36(9): 1135-1141.

7. Sarangi B, Ray HS, Tripathy KK, Sarangi A. Determination of heats of aluminothermic redox reduction of $\mathrm{V}_{2} \mathrm{O}_{5}$ and $\mathrm{MnO}_{2}$. Journal of Thermal Analysis. 1995; 44(2):441-451.

8. Cintho OM, Capocchi JDT. Utilização da moagem de alta energia no processamento de materiais. Boletim Técnico da Escola Politécnica. 2003; 0305:1-27.

9. Koch CC. The synthesis and structure of nanocrystalline materials produced by mechanical attrition: a review. Nanostrutured Materials. 1993; 2(2):109-129.

10. Murthy BS, Ranganathan S. Novel materials synthesis by mechanical alloying. International Materials Review. 1998; 43(3):101-141.

11. Suryanarayana C. Nanocrystalline materials. International Materials Reviews. 1995; 40(2):41-64.

12. Desch PB, Schwarz RB, Nash P. Mechanical alloying to produce $\mathrm{L}_{2}$ phases in the Al-Zr system. Scripta Materialia. 1996; 34(1):37-43.

13. Mahdouk K, Gachon, JC, Bouirden L. Enthalpies of formation of the Al$\mathrm{Nb}$ intermetallic compounds. Journal of Alloys and Compounds. 1998; 268(2):118-121

14. Kubaschewski O, Evans EL, Alcock CB. Metallurgical Thermochemistry. Oxford: Pergamon Press; 1974. p. 304-447. 